Jurnal Pendidikan Agama Islam Universitas Wahid Hasyim Semarang

\title{
PEMANFAATAN DIGITALISASI DALAM PENDIDIKAN ISLAM DI MASA PEMBELAJARAN JARAK JAUH (PJJ)
}

\author{
Rochmad \\ Pendidik SMAN 2 Kendal, Mahasiswa S3 UNWAHAS Semarang \\ Email: rochmadndoni@ gmail.com
}

\begin{abstract}
Abstrac
Indonesian society today is ready or not ready to be able to go through a period where every year there are always extraordinary changes both in the world of social education and culture that exist must experience changes for the progress of the existing society at this time. Especially in the era of digitalization, it has had such a huge impact on human life.

So that the rapid development in the era of the industrial revolution 4.0 resulted in many emerging learning media innovations, such as electronic communication media in the form of cellphones, television, radio, be it other electronic media or print media and so on that managed to penetrate geographical, social, and political.
\end{abstract}

Keyword: Digitalization, Islamic Education, PJJ.

\begin{abstract}
Abstrak
Masyarakat indonesia sekarang ini siap atau tidak siap harus bisa melewati masa dimana setiap tahunnya selalu mengalami perubahan yang luar biasa baik di dalam dunia pendidikan sosial serta budaya yang ada peasti mengalami perubahan untuk kemajuan masyarakat yang ada pada saat ini. Terutama di era digitalisasi membawa dampak yang begitu besar bagi kehidupan umat manusia.

Sehingga perkembangan yang pesat pada era revolusi industri 4.0 mengakibatkan banyak bermunculan inovasi media pembelajaran, seperti media komunikasi elektronik berupa handphone, televisi, radio, baik itu media elektronik yang lainnya atau media cetak dan lain sebagainya yang berhasil menembus batas geografis, sosial, dan politik.
\end{abstract}

Kata Kunci: Digitalisasi, Pendidikan Islam, PJJ. 


\section{A. Pendahuluan}

Era digital membawa dampak yang begitu besar bagi kehidupan umat manusia dewasa ini. Banyak sektor kehidupan yang mengalami perubahan dan kemajuan berkat teknologi yang dihadirkan di era ini. Pendidikan Islam sebagai subsistem pendidikan nasional juga tak bisa dilepaskan begitu saja dari keberadaan dan pengaruh teknologi informasi dan komunikasi (information and communication technology) di era digital. Bahkan keterlibatan teknologi informasi dan komunikasi dalam dunia pendidikan saat ini bukan lagi sebuah pilihan, melainkan kebutuhan mutlak yang mesti dimiliki dan dimanfaatkan pada jenjang perguruan tinggi. ${ }^{1}$

Sebagai sebuah keniscayaan akan hadirnya era digital, pendidikan Islam dituntut mampu beradaptasi atau menyesuaikan diri agar tidak tertinggal jauh dari pendidikan model lainnya. Pendidikan Islam dengan segala sumber dayanya diharapkan dapat memanfaatkan peluang era digital guna mengukuhkan eksistensinya sebagai pionir pendidikan yang unggul dan bermutu, baik dalam konteks keindonesiaan maupun dalam kancah peradaban global. $^{2}$

Era digital merupakan kondisi setiap orang dapat mengakses berbagai infomasi dalam jaringan (daring). Berbagai informasi di era ini tersedia secara bebas di dunia maya yang memudahkan siapa saja untuk mengaksesnya tanpa batas ruang dan waktu. Dunia menjadi tidak ada sekat sama sekali setalah ditemukannya sistem digital. Setiap orang terutama yang lahir sebagai digital native memiliki kecenderungan untuk mencari informasi melalui internet. Mereka lebih suka memanfaatkan fitur-fitur

${ }^{1}$ Nuryadin, "Strategi Pendidikan Islam di Era Digital", Jurnal Fitrah, Vol. 03, No. 1, Juni 2017, hlm. 212.

${ }^{2}$ Ali Mahsun, "Pendidikan Islam dalam Arus Globalisasi Sebuah Kajian Deskriptif Analitis", Jurnal Episteme, Vol. 8, No. 2, Desember 2013, hlm. 262. 
smartphone atau perangkat teknologi lain untuk berselancar di dunia maya baik untuk mencari hiburan atau untuk memenuhi kebutuhan primer. Musik dan film dapat dinikmati secara langsung atau diunduh terlebih dahulu secara gratis atau berbayar dengan tarif yang relatif murah. Untuk kebutuhan keilmuan dan akses informasi, seseorang bisa medapatkan artikel dengan bebas tanpa persyaratan sama sekali dalam dunia digital. ${ }^{3}$

Di era milenial atau juga dengan sebutan tahun serba mesin termasuk di dunia pendidikan untuk membangkitkan semangat peserta didik dalam kegiatan belajar terutama membaca membutuhkan keprihatinan yang sangat khusus. Karena peserta didik sekarang dengan kecanggihan teknologi yang ada kurang diamnfaatkan dengan sebaik-baiknya bahkan di gunakan hanya untuk senang senang saja bahkan ada yang dipaki untuk main Game Online. Maka dari itu membaca merupakan salah satu cara belajar yang efekfif untuk menambah wawasan yang ada sekarang ini.

Dengan adannya fenonema yang ada saat ini di satu sisi merupakan hal yang mengembirakan menandakan perubahan dunia ke arah yang lebih maju. Dunia digital menawarkan percepatan dalam menyelesaikan berbagai persoalan hidup dan dalam memenuhi berbagai kebutuhan manusia. Dengan sistem berbasis digital, setiap orang dapat mengurangi ketergantungan (dependence) terhadap orang lain. Digitalisasi dalam berbagai elemen kehidupan ini memudahkan siapapun untuk mencari informasi dan ilmu pengetahuan dengan cepat tanpa harus pergi ke luar rumah. Dengan bermodal jaringan internet dan perangkat keras (hardwere) dalam berbagai tipe, seluruh umat manusia dapat mewujudkan keinginannya dalam waktu yang relatif singkat. Masyarakat sangat terbantu dan dimudahkan dalam berbagai hal dengan ditemukanya dunia digital.

${ }^{3}$ Shulhan Alfinnas, "Arah Baru Pendidikan Islam di Era Digital”, Jurnal Fikrotuna, Vol. 7, No. 1, Juli 2018, hlm. 804. 


\section{B. Pendidikan Islam di masa era milenial}

Teknologi yang dikembangkan oleh ilmuan sebagai basis utama dalam pengoperasian sistem digital dapat menggiring setiap individu untuk menyibukkan diri berkomunikasi dengan dirinya sendiri. Mereka terbawa dalam suasana menikmati berbagai fasilitas yang tersedia di dunia digital. Pemanfaatan sistem digital yang berlebihan menyebabkan masyarakan menjadi individualis. Mereka sibuk dengan hand phone canggihnya dan mengabaikan terhadap keadaan lingkungan di sekitarnya. Duduk berdampingan satu kursi dalam transportasi umum tapi tidak saling bertegur sapa dan tidak saling mengenalkan diri merupakan pemandangan umum dewasa ini di Indonesia. Ini adalah contoh kecil arus dunia digital, mereduksi sensifitas sosial dan keakrabansatu sama lain. Contoh lain adalah anggota satu keluarga berkumpul dalam satu ruangan tetapi bukan asyik membincangkan satu topik dengan hangat dan penuh keakraban melainkan sibuk dengan gadget masingmasing. ${ }^{4}$

Perkembangan zaman yang telah terjadi saat ini, dengan datangnya era digital atau era revolusi industri 4.0 dapat menghasilkan dampak positif dan negatif dalam dunia pendidikan, terutama terkait pembelajaran pendidikan agama Islam yang selalu mengalami perkembangan dan perubahan secara terus menerus. Jika pada waktu silam percakapan akrab antara peserta didik dengan guru terasa tabu, maka hari ini justru merupakan hal yang wajar. Bahkan dalam pandangan teori pendidikan modern, hal itu merupakan sebuah keharusan. Interaksi semacam itu justru menjadi indikasi keberhasilan proses pendidikan. ${ }^{5}$

${ }^{4}$ Shulhan Alfinnas, "Arah Baru Pendidikan Islam di Era Digital”, Jurnal Fikrotuna, Vol. 7, No. 1, Juli 2018, hlm. 804-805

${ }^{5}$ Noor Amirudin, "Problematika Pembelajaran Pendidikan Agama Islam Di Era Digital”, Prosiding Seminar Nasional Prodi PAI UMP Tahun 2019, hlm. 181. 
Di era digital atau revolusi industri 4.0 perkembangan teknologi dan perangkat digital semakin canggih dan terus dikembangkan serta diperbarui. Gelombang peradaban tersebut membuat manusia tidak terlepas dari produk-produk digital. Bahkan semuanya kian terhubung, terbuka dan saling ketergantungan. Meski tetap memiliki wilayah teritorial dan garis pemisah yang jelas secara geografis, namun batasbatas tersebut tidak menjadi tirai penghalang untuk berinteraksi, berkomunikasi dan berbagi informasi secara terbuka oleh pengguna digital. ${ }^{6}$

Dengan adannya pergeseran pemikiran yang ada pada saat ini sehingga masyarakat di tuntut untuk mengikuti perkembangan yang ada atau paradigma lainnya misalnya dalam hal pendekatan pembelajaran. Pada era pendidikan agama Islam tradisional, guru menjadi figur sentral dalam kegiatan pembelajaran. Ia merupakan sumber pengetahuan utama di dalam kelas. Namun dalam konteks pendidikan agama Islam modern, hal demikian tidak berlaku lagi. Peran guru saat ini telah mengalami pergeseran, yakni sebagai fasilitator bagi peserta didik.

Sehingga pembelajaran pada saat ini di era digitalisasi tidak lagi berpusat pada guru (teacher centered), namun lebih berpusat pada peserta didik (student centered). Di samping paradigma di atas, ada problem lain yang dihadapi oleh pendidikan agama Islam tidak tunggal dan parsial. Ada sejumlah problem atau masalah yang masih membelit yang saling terkait satu sama lain. Misal kurangnya peningkatan kualitas sumber daya manusia dalam diri pendidik, metode pembelajaran yang klasikal, kurangnya update perkembangan teknologi, dan lain seterusnya.

\section{Implementasi Pendidikan Islam di era digital}

${ }^{6}$ Noor Amirudin, "Problematika Pembelajaran Pendidikan Agama Islam Di Era Digital”, Prosiding Seminar Nasional Prodi PAI UMP Tahun 2019, hlm. 181-182. 
Dalam agama Islam memiliki ajaran-ajaran lengkap dan sempurna. Kelengkapan dan kesempurnaan ajaran ajarannya dapat dilihat dalam berbagai aspek kehidupan baik terhadap Allah swt (habluminalaah) bahkan aspek lainya yaitu hubungan manusia dengan manusia (habluminaanasi).

Dalam hubungannya langsung dengan Allah swt agama Islam sudah mengajarkan dan memberikan tata cara khusus yang harus dilakukan oleh umat Islam seluruhnya. Tata cara yang menghubungkan langsung dengan Allah swt secara khusus adalah sholat. Sholat merupakan salah satu ibadah yang dapat menjebatani dan menghubungkan langsung batin manusia dengan Allah swt, hubungan antara makhluk dengan penciptannya. Sehingga sholat dikatakan ibadah yang paling khusus sehingga Allah mengajarkan langsung kepada rasulullah Muhammad saw melalui program isra dan miroj diharapkan umat manusia bisa menerima perintah sholat dari Allah swt langsung melalui rasulullah Muhammad saw.

Sedangkan dalam hubungannya langsung dengan sesama manusia Islam sudah mengajarkan melalui rasulullah Muhammad saw dengan cara diantarannya berdakwah. Dalam sejarah Muhammad berdakwah mempunyai keberhasilan yang luar biasa yang membuahkan keberhasilan dalam merawat persatuan dan kesatuan, salah satu cara menumbuhkan persatuan dan kesatuan dengan cara sholat berjamaah, kecintaan mereka, kedisiplinan dan keihklasan mereka dalam sholat berjamaah menumbuhkan semangat persatuan dan kesatuan serta keberanian yang tinggi diantara mereka. Disisi lain hubungan silaturrahim yang penuh kasih sayang semangat erat juga terjalin diantara mereka.

Perkembangan yang pesat pada era revolusi industri 4.0 mengakibatkan banyak bermunculan inovasi media pembelajaran, seperti media komunikasi elektronik berupa hand phone, televisi, radio, dan lain sebagainya yang berhasil menembus batas geografis, sosial, dan politis 
secara intensif. Kecanggihan alat-alat teknologi merupakan karakteristik era revolusi industri 4.0. Revolusi industri diartikan sebagai proses perubahan dalam proses produksi yang berlangsung secara cepat. Perubahan dari fase ke fase memberi perbedaan artikulatif pada sisi kegunaaannya. Fase pertama (1.0) bertempuh pada penemuan mesin yang menitikberatkan (stressing) pada mekanisasi produksi. Fase kedua (2.0) sudah beranjak pada tahap produksi massal yang terintegrasi dengan quality control dan standarisasi. Fase ketiga (3.0) memasuki tahapan keseragaman secara massal yang bertumpu pada integrasi komputerisasi. Fase keempat (4.0) telah menghadirkan digitalisasi dan otomatisasi perpaduan internet dengan manufaktur. ${ }^{7}$

Konsepsi teknologi pendidikan dapat diketahui melalui pendekatan teknologi atau pendidikan. ${ }^{8}$ Secara pendekatan teknologi, teknologi pendidikan diartikan sebagai keseluruhan metode yang secara rasional mengarah dan memiliki ciri efisiensi dalam setiap bidang kegiatan manusia. Dalam dunia industri, produksi menggunakan teknologi ini akan menghasilkan produk yang lebih banyak (efisiensi dalam penggunaan teknologi). Teknologi dalam pendidikan adalah sarana dan keperluan yang menunjang berjalannya kegiatan pendidikan. Teknologi pendidikan adalah proses sistematis dalam usaha mendidik atau membelajarkan peserta didik. Pengertian teknologi pendidikan bukan terbatas pada alat pendidikan, namun lebih pada metode atau cara dalam praktik pendidikan dengan langkah-langkah efektif terhadap inovasi dalam pembelajaran yang lebih sistematis ke depannya.

${ }^{7}$ Hendra Suwardana, "Revolusi Industri 4.0 Berbasis Revolusi Mental”, Jurnal Jati Unik, Vol. 1, No. 2, 2017, hlm. 102-110.

${ }^{8}$ Noor Amirudin, "Problematika Pembelajaran Pendidikan Agama Islam Di Era Digital”, Prosiding Seminar Nasional Prodi PAI UMP Tahun 2019, hlm. 181-182. 
Salah satu penggunaan teknologi di era ini adalah dengan adanya teknologi komunikasi. Pemaknaan para ahli dalam menilai adanya teknologi komunikasi tidak hanya berupa alat-alat namun lebih pada proses pendidikan dan pembelajaran. Dalam dunia pendidikan teknologi komunikasi diartikan sebagai ilmu cara berhubungan. Pendidikan bukan memuat berapa banyaknya pesan-pesan pembelajaran, namun perlu cara atau teknik bagaimana agar pesan tersebut dapat ditransformasikan kepada peserta didik. ${ }^{9}$

Berkembangnya era 4.0 adalah momentum bagi guru agar proses pembelajaran hendaknya dapat meningkatkan kualitas kompetensi pribadi dan peserta didik. Pemanfaatan teknologi berupa alat-alat canggih masa sekarang diimbangi dengan kemampuan melakukan metode efisien yang tertata dengan baik dalam mengenyam pendidikan sebagai upaya transferisasi ilmu. Dalam hal ini, guru cenderung akan memanfaatkan alatalat ataupun produk (media) teknologi yang mereka anggap dapat membantu dalam proses pembelajaran sehingga perlu menjadi perhatian bagi para pengembang teknologi pembelajaran. ${ }^{10}$

Salah satu penggunaan teknologi di era ini adalah dengan adanya teknologi komunikasi. Pemaknaan para ahli dalam menilai adanya teknologi komunikasi tidak hanya berupa alat-alat namun lebih pada proses pendidikan dan pembelajaran. Dalam dunia pendidikan teknologi komunikasi diartikan sebagai ilmu cara berhubungan. Pendidikan bukan memuat berapa banyaknya pesan-pesan pembelajaran, namun perlu cara

\footnotetext{
${ }^{9}$ Maswan dan Khoirul Muslimin, "Teknologi Pendidikan: Penerapan Pembelajaran yang Sistematis”, (Yogyakarta: Pustaka Pelajar, 2017), hlm 196.

${ }^{10}$ Akhmad Syahri, "Spirit Islam dalam Teknologi Pendidikan di Era Revolusi Industri 4.0”, Jurnal Attarbiyah, Vol. 28, 2018, hlm. 62-80.
} 
atau teknik bagaimana agar pesan tersebut dapat ditransformasikan kepada peserta didik. ${ }^{11}$

Pendidikan Islam terutama di era digital dimaksudkan untuk membentuk generasi muslim yang cakap ilmu dan keterampilan agar mampu melangsungkan hidup dengan baik, aman, sejahatera dan harmonis. Formulasi pendidikan Islam dirancang untuk melatih, dan membina setiap individu muslim agar cakap dalam keilmuan Islam dan pengamalannya dalam setiap hari dan cakap dalam ilmu praktis berbasis terapan untuk mengelola sumber daya alam sebagai upaya untuk memenuhi kebutuhan sehari-hari. Peserta didik melalui pendidikan ini dididik dalam aspek batin yang berhubungan erat dengan keimanan dan karakter dan juga aspek lahir yang berhubungan dengan keterampilan mencari nafkah sebagai tanggung jawab pribadi untuk mencukupi kebutuhan pokok untuk diri, keluarganya serta masyarakat sekitar yang membutuhkan pertolongan. ${ }^{12}$

Untuk mewujudkan cita-cita luhur tersebut, pegiat pendidikan khususnya yang membidangi pendidikan Islam dituntut untuk mampu memaksimalkan potensi positif yang terdapat dalam dunia digital dan meminimalisir aspek negatif yang timbul dari munculnya media tersebut. Pendidik seyogyanya mampu melakukan inovasi desain pembelajaran dengan memanfaatkan dunia digital. Kemunculan barang itu yang telah menguasai hampir seluruh dimensi kehidupan anak muda tidak dapat dielakkan lagi. Menjauhkan anak-anak dari bersinggungan dengan dunia maya bukan pilihan yang terbaik tetapi membiarkan mereka terlalu bergantung dengan segala hal yang berhubungana dengan dunia informasi digital tanpa kontrol dan pengarahan merupakan keputusan yang berisiko

${ }^{11}$ Maswan., Khoirul Muslimin, Teknologi Pendidikan, hlm 196.

${ }^{12}$ Shulhan Alfinnas, “Arah Baru Pendidikan Islam di Era Digital”, Jurnal Fikrotuna, Vol. 7, No. 1, Juli 2018, hlm. 805. 
tinggi. Langkah terbaik adalah memanfaatkannya untuk perkembangan pendidikan mereka dengan menyusuan strategi konten dan model pembelajaran berbasis digital dengan visi besar untuk mewujudkan generasi muslim yang menjangkau hasanah hidup. ${ }^{13}$

Tuhan Allah SWT memberikan suatu ujian baik itu melalui musibah wabah Corona (Covid 19) ini tentunya mempunyai banyak manfaat dan kebahagiaan tentunya bagi orang-orang yang beriman dan menyakini adannya Qodha dan Qodhar Allah SWT akan tetapi bagi orang orang yang kurang beriman atau tidak menyakini adannya Qodha dan Qodar tentu ini suatu kemarahan atau kemurkaan Allah SWT kepada umat manusia di muka bumi ini.

Manfaat yang lain diantaranya banyak sekarang khususnya bagi guru yang bisa mengoprasionalkan bahkan para guru bisa berkembang sangat pesat dalam pembuatan media pembelajaran bahkan mereka bisa mempunyai konten sendiri berupa You tube dimana mereka bisa membuat vidio sendiri sehingga bisa di kirim ke peserta didiknya, bahkan yang terbaru adalagi yang namanya Tiktok ini juga bisa di gunakan untuk media pembelajaran yang kreatif dan inovatif bagi para guru dan pendidik lainnya.

\section{KESIMPULAN}

Pendidikan Islam terutama di era digital dimaksudkan untuk membentuk generasi muslim yang cakap ilmu dan keterampilan agar mampu melangsungkan hidup dengan baik, aman, sejahatera dan harmonis. Untuk mewujudkan cita-cita luhur tersebut, pegiat pendidikan khususnya yang membidangi pendidikan Islam dituntut untuk mampu memaksimalkan potensi positif yang terdapat dalam dunia digital dan hlm. 805 .

${ }^{13}$ Shulhan Alfinnas, "Arah Baru Pendidikan Islam di Era Digital”, Jurnal Fikrotuna, 
Jurnal Pendidikan Agama Islam Universitas Wahid Hasyim Semarang

meminimalisir aspek negatif yang timbul dari munculnya media tersebut. Pendidik seyogyanya mampu melakukan inovasi desain pembelajaran dengan memanfaatkan dunia digital.

\section{DAFTAR PUSTAKA}

Alfinnas, Shulhan, "Arah Baru Pendidikan Islam di Era Digital", Jurnal Fikrotuna, Vol. 7, No. 1, Juli 2018.

Amirudin, Noor, "Problematika Pembelajaran Pendidikan Agama Islam Di Era Digital”, Prosiding Seminar Nasional Prodi PAI UMP Tahun 2019.

Mahsun, Ali, "Pendidikan Islam dalam Arus Globalisasi Sebuah Kajian Deskriptif Analitis", Jurnal Episteme, Vol. 8, No. 2, Desember 2013.

Maswan dan Khoirul Muslimin, "Teknologi Pendidikan: Penerapan Pembelajaran yang Sistematis", Yogyakarta: Pustaka Pelajar, 2017.

Nuryadin, "Strategi Pendidikan Islam di Era Digital", Jurnal Fitrah, Vol. 03, No. 1, Juni 2017.

Suwardana, Hendra, "Revolusi Industri 4.0 Berbasis Revolusi Mental", Jurnal Jati Unik, Vol. 1, No. 2, 2017.

Syahri, Akhmad, "Spirit Islam dalam Teknologi Pendidikan di Era Revolusi Industri 4.0", Jurnal Attarbiyah, Vol. 28, 2018. 